Tomasz Sobieraj

Instytut Filologii Polskiej, Uniwersytet im. Adama Mickiewicza w Poznaniu

\title{
O dynamice i opozycjach XIX-wiecznej kultury ${ }^{1}$
}

W Stowie wstępnym do swojej monografii Sabina Brzozowska poruszyła problem niestabilności, relatywizacji, a nawet dezaktualizacji wcześniejszych konstrukcji periodyzacyjnych i nazewniczych, które nakładano na historycznoliteracką materię schyłku xIx i początku xx wieku. Badaczka - w pełni świadoma coraz mniejszej przydatności niegdysiejszych podziałów okresowych - nie opowiedziała się wszakże za żadnym pojęciem scalającym tę płaszczyznę przedmiotową, podkreśliła bowiem jej, by tak rzec, dynamiczną labilność i wewnętrzną antynomiczność, nadto przenikający ją wielowątkowy dialog z tradycją kulturową (przede wszystkim romantyczną). Owszem, w swoim dyskursie autorka posługuje się nierzadko kategoriami XIX-wieczności, nowoczesności i modernizmu, jednak czyni to zawsze w sposób umiejętnie sfunkcjonalizowany, ukazując np. miejsce literatury i kultury Młodej Polski w ogólnoeuropejskich przestrzeniach idei i estetyki, powiązanych $\mathrm{z}$ tamtymi kategoriami. Uzasadniając zaś utworzoną przez siebie

1 Recenzja książki Sabiny Brzozowskiej [2018] pt. W zwierciadle idei. Literatura Młodej Polski - konteksty. 
konstelację obejmującą twórczość Wacława Berenta, Stanisława Wyspiańskiego i Tomasza Manna, stwierdziła:

Eksperyment może i na pierwszy rzut oka niedorzeczny, ale jeśli potraktujemy sztukę jako wartość autoteliczną, mit jako przestrzeń do wypełnienia, zagadnienie narodowości sztuki jako refleksję nad istotą nowoczesnego społeczeństwa i narodu [...], to otrzymujemy paradoksalnie spójny obraz - ale zagęszczony, pouzupełniany o różne scenografie i różne odcienie podobnych myśli i emocji. [Brzozowska 2018: 9-10]

Obraz ten współtworzą w monografii studia skupione wokół trzech zasadniczych węzłów tematycznych. Pierwszy obejmuje modernistyczny dramat i teatr, znaczony nazwiskami tej miary co: Wyspiański, Miciński, Przybyszewski i Rittner, drugi dotyczy twórczości Tomasza Manna, powiązanej intertekstualnie z literaturą polską (Wyspiański), wreszcie trzeci - modernistycznej prozy Wacława Berenta i Tadeusza Micińskiego. Całość, którą dałoby się ogólnie określić jako harmonijnie ze sobą powiązane wariacje na temat XIX-wiecznej topiki ideowej i artystycznej, składa się z 11 rozdziałów. Każdy jest rozbudowanym i pogłębionym opracowaniem danego problemu oraz poświadcza duże kompetencje autorki, jej rozległą orientację historycznoliteracką i komparatystyczną, swobodne panowanie nad obfitą literaturą przedmiotu, a także wielką inwencję interpretacyjną.

Rozdział pierwszy, poświęcony dramatowi Śnieg Stanisława Przybyszewskiego, to jedno z najlepszych odczytań tego utworu w dziejach jego recepcji historycznoliterackiej i historycznoteatralnej. Kapitalnym pomysłem okazało się tu zastosowanie do interpretacji tego dzieła klucza poetyki filmowej; wcześniej tym tropem nie podążano ${ }^{2}$. Tymczasem Brzozowska przekonująco udowodniła, poznawczej, na symbolice postaci i jej strukturze podmiotowej, na metafizycznej koncepcji świata przedstawionego, na związkach z tradycją literacką i prądami współczesnymi, na poetyce dzieła wreszcie [zob. Eustachiewicz 1982: 145; Taborski 1987: 5-12; Sajewska 2002: 123-149; 2006: 307-309, 312-317]. 
że Przybyszewski umiejętnie operował zasadą konstrukcyjną przypominającą kompozycje melodramatów filmowych, albowiem „filmowo i melodramatycznie rozplanował sceniczny ruch, wprowadzając napięcie pomiędzy parą protagonistów”. W rezultacie, czytamy dalej, „[w] rozgrywanej tu i teraz śmiertelnej walce płci rodem ze Strindberga uwagę odbiorcy skupia ostentacja zachowań postaci, ich mowa ciała, mimika i spojrzenia [...]” [Brzozowska 2018: 22]. W strukturze Śniegu - a także innych dramatów Przybyszewskiego - ścierałyby się rozmaite elementy konstrukcyjne i treściowe: poetyka symbolizmu, kod nieświadomości i zdarzenia naznaczone „symetrią melodramatycznej” fabuły.

Historycznoliteracką i historycznoteatralną optykę zastosowała autorka w szkicu o Tadeuszu Rittnerze jako autorze $W$ małym domku oraz krytyku teatralnym. Twórczość pisarza sytuuje się tu w kontekście nowych (podówczas) prądów artystycznych i związanych z nimi tendencji ideowych, przede wszystkim naturalizmu Henrika Ibsena i Émile’a Zoli. W swoim dramacie Rittner zawarł wnikliwą diagnozę sytuacji międzyludzkich, przedstawiając ją za pomocą stonowanych półcieni, niedopowiedzeń oraz ironii. W sztuce zarysowuje się wielowymiarowość i wielogłosowość świata, znakomicie modelowana poprzez struktury dialogowe tekstu. Jak bowiem przekonuje autorka:

Dialog w sztuce Rittnera portretuje wewnętrzny rozpad postaci, ich „fałszywą świadomość”, oddaje również różnice w postrzeganiu tej samej sytuacji czy przedmiotu przez różnych bohaterów, budując w ten sposób pełny, wielowymiarowy obraz świata przedstawionego. Dramat daje wszak dojść do głosu różnym punktom widzenia, nakreśla odmienne perspektywy. [Brzozowska 2018: 57]

Sens globalny dramatu Rittnera sprowadza się do problemu prawdy, która stała się, jak wiadomo, jednym z najistotniejszych składników światopoglądu artystycznego Ibsena, silnie oddziałującym na całą dramaturgię europejską tamtej doby. Rittner przedstawia rozmaite społeczne warianty prawdy o człowieku oraz jego funkcjonowanie w sieci opinii środowiskowych, a także 
iluzji i kłamstw³. Dramat zawiera znaczny potencjał sceniczny, z kolei psychika postaci została wycieniowana i przedstawiona w sposób zróżnicowany. Walory $W$ małym domku poświadczają znakomite autorskie wyczucie praw rządzących sceną teatralną. Kreacje bohaterów dramatu to, rzec można, partytury teatralne, konkretyzowane w sztuce aktorskiej. Rozwijając spostrzeżenie Artura Hutnikiewicza, Brzozowska subtelnie zauważyła: „Rittner z szarej materii dnia codziennego wydestylował delikatnie mieniący się metaforami teatr. W ten sposób udało mu się odsłonić puste struktury ról społecznych" [Brzozowska 2018: 61].

W wyrazistą sekwencję problemowo-tematyczną układają się pozostałe fragmenty monografii skupione na zagadnieniach dramaturgii i teatru. Na plan pierwszy wysunęła tu autorka twórczość Stanisława Wyspiańskiego i Tadeusza Micińskiego. W rozdziale siódmym przedstawiła wielki spór z tradycją myślową polskiego romantyzmu, prowadzony przez Wyspiańskiego za pomocą intertekstualnych gier motywami antycznymi (poprzedniczką Brzozowskiej była na tym polu Hanna Filipkowska [1973]). Obiektem analiz uczyniła tutaj Legion, Wyzwolenie oraz Noc listopadowa. Koncepcja skontaminowania modelu kultury antycznej z romantyzmem nie jest tu, rzecz jasna, zabiegiem ani przypadkowym, ani nieumotywowanym. Brzozowska przekonuje bowiem, iż może ona służyć egzegezie sensów globalnych literatury młodopolskiej, konkretnie zaś - dramatów Wyspiańskiego. To w romantyzmie doszło -zdaniem autorki - do sytuacji, w której

[t]radycja antyczna przefiltrowana przez ekran romantyzmu straciła monolityczny charakter, stała się zjawiskiem heterogenicznym, traktowanym w wielostronny sposób. Weryfikacji został poddany rejestr antycznych bohaterów, a sam bohater stał się sygnaturą określonych - aczkolwiek naznaczonych indywidualnym piętnem - przeżyć, bądź korespondował 406-407], która napisała, iż: „Prawdziwe relacje między małżonkami [bohaterami $W$ matym domku - T.S.] zakryte były [... ] nawet dla nich samych; i w tym odkryciu Rittner idzie tropem Ibsena, który pierwszy pokazał, że życie człowieka spowijają nie uświadamiane sieci kłamstw”. 
z ewokowaną przez legendy Pólnocy atmosferą grozy i niepokoju. [Brzozowska 2018: 185]

Motywy antyczne, splecione z romantycznymi, tworzyły w dramaturgii Wyspiańskiego struktury mitu. W trzech analizowanych przez Brzozowską utworach eksponowani są bohaterowie o wyraźnej proweniencji romantycznej, naznaczeni jawną literackością. Wyspiański - czego przekonująco, a niekiedy błyskotliwie dowodziła autorka - dekonstruowal, by tak rzec, romantyczną świadomość Polaków, w tym m.in. mesjanizm jako bardzo popularną ofertę historiozoficzną, przenikającą też na poziom myślenia potocznego. Zdaniem Brzozowskiej: „[...] Ostatnia Wieczerza Mickiewicza i dwunastu legionistów to najbardziej sugestywny znak negacji mesjanizmu" [Brzozowska 2018: 194]. Główny bohater Legionu - Mickiewicz - został przez Wyspiańskiego przybrany w „maskę frenetycznego szaleńca”, ujęty w „intertekstualny tygiel, narzucający mu przyjmowanie wciąż nowych ról” [Brzozowska 2018: 195]. Z kolei bodaj najważniejszy z protagonistów poety, Konrad z Wyzwolenia, istnienie swoje przeżywa w formie nieustannej kreacji, przy czym jawi się jako „niewolnik sceny”, zamknięty w „sztucznej przestrzeni teatru”, naznaczony romantyczną „gębą" [Brzozowska 2018: 203]. Kapitalnie brzmi lapidarna formuła autorki: „Konrad to również aktor, który gra Konrada, bohatera romantycznego $\mathrm{w}$ tradycyjnym dramacie narodowym" [Brzozowska 2018: 203]. Sam dramat układa się w grę iluzji i deziluzji, pochłaniającą protagonistę swoją coraz intensywniejszą teatralizacją, co w rezultacie prowadzi do tego - jak efektownie konkluduje Brzozowska - iż „znalazł się [on - T.S.] w niedorzecznej i paradoksalnie wiarygodnej, Gombrowiczowskiej sytuacji” [Brzozowska 2018: 206]. Literacka proweniencja Konrada oraz jego liczne koneksje antyczne nadały Wyzwoleniu znamiona wyrafinowanej konstrukcji intertekstualnej. Cały ten wewnętrznie złożony i zróżnicowany konterfekt protagonisty autorka kompetentnie zrekonstruowała, sumiennie odnotowując wcześniejsze ustalenia badawcze. Zauważając, iż Konrad chciałby poprzez sztukę „kształtować świat zewnętrzny" [Brzozowska 2018: 197], sugeruje ona swoiście performatywny wymiar dramatu Wyspiańskiego. W Wyzwoleniu zawiera 
się bowiem wizja sztuki czynnościowej, wysokiej, aktywistycznej, pragmatycznie nastawionej na rewizję świadomości kulturowej Polaków, atakującej postromantyczny mesjanizm z jego pasywizmem, biernością i kultem cierpienia. Kwestie te nie znalazły się w centrum uwagi autorki; zdecydowanie bardziej interesował ją bowiem splot tradycji antycznej z topiką romantyczną, zorientowany w stronę prawd natury antropologiczno-metafizycznej. Sieć intertekstualnych powiązań antycznych tworzyła w dramatach Wyspiańskiego wyraziste - acz niejednoznaczne - uniwersum kulturowe, w którym sytuował on swoich bohaterów romantycznych, konfrontując ich zarazem z problemami swojej współczesności. Zdaniem autorki przywoływane przez poetę figury bohaterów antycznych

potwierdzają status bohatera romantycznego w polskiej kulturze: wiecznego poszukiwacza prawdy, będącego jednocześnie zwycięzcą i pokonanym, czyli postacią wierną zarówno poetyce mitu, jak i romantycznej dialektyce. [Brzozowska 2018: 207]

Znakomity poziom merytoryczny prezentuje rozdział Od agonu do groteski. Dynamika słowa u Wyspiańskiego i Micińskiego. Jest to rozległa, pogłębiona i wielokontekstowa analiza skomplikowanych więzi łączących dorobek twórczy i myśl estetycznoteatralną oraz filozoficzną obu tych artystów. Autorka sumiennie potraktowała cały korpus dotychczasowej literatury przedmiotu poświęconej temu zagadnieniu. Wyspiański i Miciński to dwaj wybitni nowatorzy polskiego dramatu i teatru modernistycznego, nierzadko ze sobą konfrontowani, natomiast w ujęciu Brzozowskiej sytuujący się wobec siebie na zasadzie agonu i wpływu ${ }^{4}$. O ile Wyspiański miał okazje, by częściowo realizować swoje wizje artystyczne na scenie (zresztą nie bez oporów), to z kolei program estetycznoteatralny Micińskiego pozostał w sferze potencjalnej. Niezmiennie napotykał on bariery stawiane przez ludzi niegotowych na jego

4 Odwołując się do słynnej koncepcji Harolda Blooma, Brzozowska [2018: 216] zasugerowała, iż: „W spotkaniu Wyspiański-Miciński autor Bazylissy zdaje się być tym, który ściga spełnionego artystę teatru”. 
eksperymenty artystyczne. W ogłoszonym w 1905 roku manifeście Teatr-Światynia z przekąsem napisał o Józefie Kotarbińskim jako dyrektorze teatru krakowskiego:

Potrzeba uczuć się arcykapłanem świątyni, umieć pielęgnować Znicz nie względami praktycznymi i tego, aby decorum w obrachunku rocznym było przed rajcami miejskimi, lecz aby naród w teatrze duchem rosnął.

Nie lubię wywlekać własnych spraw, lecz one bywają znamienne. Lat temu ośm byłem dla pana Kotarbińskiego autorem dramatycznym (Żywioty, Marcin Łuba), teraz jestem fantastą w Nocy Rabinowej, a piszącym na zbyt drogie dekoracje w mej ostatniej historycznej tragedii.

Należy się spłaszczyć do kiepskiego humoru i elukubracji z jakąś miłosną intryżką, i postrącać swoje wierzchołki, albo się nie daje gwarancji, że się przejdzie przez rampę

Manifest ten został przez Micińskiego obmyślany jako głos za kandydaturą Wyspiańskiego na stanowisko dyrektora teatru w Krakowie, przede wszystkim jednak okazał się - jak napisała Brzozowska - „eksplozją postulatów, poglądów i ekspresywnych wizji Micińskiego, dotyczących kształtu współczesnego teatru” [Brzozowska 2018: 214]. I Miciński, i Wyspiański wyznawali ideę teatru o rozległych horyzontach metafizyczno-etycznych; tak ujawniali sposób myślenia o sztuce scenicznej właściwy młodopolskiej estetyce teatru. W Królewnie Orlicy, dramacie powstałym najprawdopodobniej między 1915 a 1917 rokiem, nawiązał Miciński do Wesela i Wyzwolenia, licząc na to, że - jak ujęła to badaczka - sztuka okaże się „wstrząsem, pobudką dla publiczności, wpłynie na bieg historii” [Brzozowska 2018: 217]. Tak się oczywiście nie stało...

Oryginalny wydźwięk ma w tym rozdziale hipoteza interpretacyjna Brzozowskiej, akcentująca motyw agonu, jaki zaistniał między Wyspiańskim i Micińskim, motyw zogniskowany na tym, iż artyści ci walczyli ze sobą „nie na argumenty - obaj użyliby podobnych - ale na teatralne realizacje i estetyki” [Brzozowska 2018: 224]. 
Właśnie w Królewnie Orlicy dostrzegła badaczka opozycyjną wobec Wesela propozycję artystyczną. Jeśli bowiem Wyspiański oferował „teatr myśli”, zorientowany na ewokowanie sceny sądowej, na której rozgrywałby się dramat jako „proces publiczności-narodu”, to Miciński „rzucił się w morze aluzji literackich, symboli, mitów” i projektował swój teatr jako „egzorcyzmowanie współczesności obrazami z teatrów osobliwości” [Brzozowska 2018: 224]. Jeśli dobrze rozumiem autorkę, to różnicę między Wyspiańskim a Micińskim (uwidocznioną w zestawieniu Wesela z Królewną Orlica) sprowadza ona do nieco odmiennych funkcji teatru i języka poetyckiego. Autor Wesela i Wyzwolenia demistyfikował polską rzeczywistość za pomocą wielkich figur pojęciowych: Czyn, Los, Wola, Słowo, ukazując pozbawioną wewnętrznej prawdy zbiorowość w stanie bezwładu, inercji, pustych gestów. Z kolei Miciński miał nadawać słowu większą moc i dynamikę, dzięki czemu możliwe było tworzenie polifonicznego obrazu świata [Brzozowska 2018: 224].

Wyrazistą i spójną tematycznie sekwencję monografii tworzą studia z zakresu komparatystyki historycznoliterackiej oraz historyczno-kulturowej zarazem; są to: rozdział trzeci: Mit i egzystencja w „Czarodziejskiej górze” Tomasza Manna, rozdział czwarty: Mann wedtug Berenta. Czarodziejska „Ozimina”, rozdział piąty: „Wesele” Stanistawa Wyspiańskiego i „Buddenbrookowie” Tomasza Manna. Dopetniająca się historia.

We wszystkich tych rozdziałach autorka posłużyła się formacyjnymi kategoriami pojęciowymi: głównie XIX-wiecznością. Na przykład Czarodziejska góra Manna została tu wnikliwie zinterpretowana jako powieść diagnozująca świadomość kulturową przełomu XIX i xx wieku oraz schyłek liberalnej kultury mieszczańskiej. Portrety duchowe bohaterów oraz ich losy powieściowe układają się jak wariacje na wielkie tematy mityczne, nad nimi zaś nadbudowują się określone kody symboliczne. Rozdział o Czarodziejskiej górze to wzorcowe studium o charakterze kulturowym, poświadczające znakomitą orientację autorki w uniwersum kultury europejskiej od czasów antyku, w tym m.in. w antropologii filozoficznej Nietzschego. Wydawać by się na pozór mogło, że trudno już odkryć nowe aspekty semantyki powieści Manna. Tymczasem 
czytelnik książki Brzozowskiej natrafia w rozdziale o Czarodziejskiej górze na subtelną opowieść o skomplikowanym procesie dojrzewania Castorpa, przedstawionym jako wielostopniowe wtajemniczenie w prawa bytu. Proces ów mieni się w powieści wieloma barwami, traci, rzec można, swoją materialną substancjalność, jako że przekształca świat przedstawiony w rzeczywistość ulotną, eteryczną, widmową ${ }^{6}$. Zaakcentowanie metafizycznego horyzontu sensów powieściowej fabuły zostało uwieńczone $\mathrm{w}$ finale rozdziału efektowną supozycją o - zobrazowanym w Czarodziejskiej górze „symboliczn[ym] złożeni[u] do grobu dawnego świata XIX wieku [...]" [Brzozowska 2018: 98].

Przykładem nowoczesnej komparatystyki kulturowej okazuje się czwarty rozdział monografii, poświęcony interpretacji swoistych miejsc wspólnych powieści Manna i Berenta, korespondujących ze sobą pod względem ideowo-poznawczym i artystycznym. Cała konstrukcja myślowa wywodu zasadza się tu na efektownym wyjściowym założeniu, w którym - jak czytamy na wstępie - chodziło o:

tropienie źródeł wyobraźni, intelektualnych fascynacji, niepokojących podobieństw (i oczywistych różnic) w konstrukcji świata przedstawionego i w finezji języka; o wyśledzenie swoistej mapy „zrywów umysłowych”, „kolorytu duchowego”, wreszcie - obecnych w obu powieściach pomruków czy też gromów Historii na progu wieku xx, no i politycznych konceptów, w których być może dostrzegalne okażą się zwierciadlane odbicia tych samych idei. [Brzozowska 2018: 99]

Autorka zarysowała sieć podobieństw w biografiach Manna i Berenta, nadto odnalazła w ich twórczościach elementy pozwalające na utworzenie swoistej konstelacji ideowo-artystycznej.

6 Autorka stwierdziła np.: „Można odnieść wrażenie, że im bardziej Castorp angażował się w życie «Berghofu», tym bardziej milkły głosy dysput, a zaczarowany świat paradoksalnie pustoszał. Taneczny wir misterium gwałtownie przyspieszył, pełnokrwiste osobowości stawały się zamazanymi smugami, widmami” [Brzozowska 2018: 95]. 
Dla obu pisarzy [zauważyła badaczka - T.S.] kluczowe wydaje się zagadnienie inteligencji: jej kondycji, stanu umysłu, rachunków sumienia, artystowskiego uwikłania, powinności, postaw etycznych i włączenia w świat mieszczański [...]”. [Brzozowska 2018: 101]

Ciekawym pomysłem interpretacyjnym jest ujęcie Buddenbrooków oraz Próchna jako swoistych antycypacji powieści późniejszych: odpowiednio Czarodziejskiej góry i Oziminy. Właściwie wszystkie cztery utwory przynoszą diagnozy duchowości inteligenckiej ( w tym artystowskiej), osadzonej, rzecz jasna, w nieco odmiennym kontekście społeczno-ekonomicznym i kulturowym. Znakomity efekt przyniosły w tym rozdziale rozważania Brzozowskiej na temat czasowego komponentu fabuł Czarodziejskiej góry i Oziminy, który uwidocznia się na różne sposoby (zarówno eksplicytny, jak i implikowany), a przy tym nierzadko wplata się w porządek mityczny. Protagoniści powieści Manna i Berenta dojrzewają, wtajemniczając się w życie i historię oraz uczestnicząc w dyskusjach o dużym potencjale znaczeniowym. Nad kompozycjami fabularnymi obu powieści nadbudowują się, jak trafnie przekonuje autorka, kody mityczne oraz zmetaforyzowane układy sensów.

Podobną strategię kompozycyjną - opartą na podejściu właściwym komparatystyce kulturowej - zastosowała autorka w piątym rozdziale monografii, konfrontując ze sobą Buddenbrooków i Wesele (wprawdzie taką paralelę wykoncypowała parę lat temu Maria Prussak, co autorka sumiennie odnotowała, jednak tamto spostrzeżenie nie wykroczyło swoim zasięgiem poza lakoniczną wzmiankę). Ta konstrukcja myślowa nie wygląda na przypadkową; przeciwnie - Brzozowska potrafiła przekonująco uzasadnić swoją koncepcję egzegetyczną.

Odrębność tekstów w ujęciu synchronicznym [pisze autorka T.S.] ulega zniwelowaniu: wydaje się, że zarówno Buddenbrooków, jak i Wesele można by potraktować [...] jako teksty o poszukiwaniu własnego tonu, o autonomii sztuki i jednostki, o zmaganiu z przeszłością, a nawet jako teksty włączające w swój obręb zagadnienie (wtórnej) mityzacji rzeczywistości. 
A Wyspiańskiego i Manna po prostu - jako modernistycznych artystów europejskich [...]. [Brzozowska 2018: 126]

Wiele wątków tej porównawczej interpretacji obu utworów zdumiewa swoją pomysłowością i odkrywczością. Na jeden zwrócitbym uwagę: teatralność świata w Buddenbrookach i Weselu, silnie oddziałująca i na modus bohaterów (u Manna), i na całą koncepcję świata przedstawionego (u Wyspiańskiego). Obydwa dzieła na swój sposób syntetyzują doświadczenie nowoczesności XIX-wiecznej, ukazując meandry losów jednostkowych, splecionych z historią wspólnoty. Postawione przez obu pisarzy diagnozy stanu współczesnej kultury odwzorowują, rzecz jasna, dylematy właściwe historii już to Niemiec, już to Polski rozbiorowej. W toku rozważań autorki wyłaniają się zadziwiające powinowactwa ideowo-światopoglądowe między Buddenbrookami a Weselem, przejawiające się np. w konfrontacji teraźniejszości z przeszłością, w poszukiwaniu formuly egzystencji, w dyskusjach nad miejscem sztuki w życiu jednostkowym i społecznym, wreszcie także w zastosowaniu ironii [zob. Brzozowska 2018: 156].

W rozdziale szóstym - Dürer - Berent - Kristeva: tropy melancholiczne w „Próchnie” Wactawa Berenta - autorka rozwinęła błyskotliwą interpretację układu „tropów melancholicznych" powieści, rekonstruując portrety duchowe kilku jej bohaterów. To pierwsze tak dogłębne i rozległe zarazem ujęcie tej problematyki w literaturze przedmiotu poświęconej Próchnu. Ze szczególnym uznaniem odnotowuję interpretację Władysława Borowskiego - aktora, postaci nie w pełni dotąd, jak sądzę, rozszyfrowanej w literaturze przedmiotu. Ten człowiek „przedmiotowy" (w systematyce Nietzschego) został przez autorkę ujęty przez pryzmat doświadczenia melancholijnego, na które znacząco wpłynęły skomplikowane relacje bohatera z matką i ojcem. Odgrywanie własnych losów - wyznaczające egzystencjalne modi zarówno Borowskiego, jak i np. Jelsky’ego - stanowiło istotny składnik podmiotowości modernistycznej. W zaproponowanej przez Brzozowską interpretacji postaci dziennikarza na plan pierwszy wysuwa się trop dandysowski, stanowiący oryginalny pogłos Mefistofelesa. 
Rozdział dziewiąty monografii to z kolei nowatorskie opracowanie światopoglądowo-filozoficznej oraz estetycznej paraleli Słowacki - Miciński. Brzozowska momentami wręcz wirtuozowsko zarysowuje miejsca wspólne i różnice obecne zarówno w wielkich projektach teatralnych obu poetów, jak i w ich spojrzeniach na historię oraz doświadczenie jednostki na przestrzeni dziejów. Podkreślić pragnę ujawnianą przez Autorkę kompletną znajomość kontekstu historycznoliterackiego oraz historycznoteatralnego: od romantyzmu po eksperymenty awangardy teatralnej początku $\mathrm{xx}$ wieku.

Rozdziały dziesiąty i jedenasty dopełniają konstelację Micińskiego. Pierwszy z nich skupia się na powieści Wita jako swego rodzaju romansie grozy, zespalającym w swojej strukturze konwencje gatunkowe tej odmiany powieści z problematyką historiozoficzną. To świetna, wielopłaszczyznowa analiza i interpretacja nie tylko poetyki Wity, lecz także stylów odbioru powieści w dwudziestoleciu międzywojennym oraz wielu zabiegów mitologizacyjnych stosowanych przez Micińskiego wobec bohaterki tytułowej i postaci księcia Józefa.

W ostatnim rozdziale monografii - Miciński - Klata. „Termopile polskie" w teatralnym lustrze XxI wieku - Brzozowska poszerzyła terytorium swoich badań o enklawę współczesnego teatru polskiego, ściślej: twórczość Jana Klaty, reżysera wrocławskiej premiery Termopil polskich w 2014 roku. Autorka zna właściwie całość recepcji krytyczno- oraz historycznoliterackiej dramatu; ze swobodą przywołuje stan badań, podporządkowując go własnej koncepcji egzegetycznej (jest to zresztą wielki walor całej monografii, nie tylko ostatniego rozdziału). Z pewnym dystansem natomiast potraktowała premierę dramatu w reżyserii Klaty. Nie miałem, niestety, okazji widzieć tego spektaklu, dlatego też nie mam podstaw merytorycznych, by podejmować dyskusję z autorką książki. Odnoszę jednak wrażenie, że ma ona pewne pretensje do reżysera o spłycenie dramatu Micińskiego; pisze wszakże otwarcie:

Termopile polskie Jana Klaty tracą [...] na wieloznaczności, zaczynają dryfować ku jednej z wielu estetyk obecnych u Micińskiego - w stronę groteski; operują nieskompliko- 
wanymi skojarzeniami: pole bitwy - bokserski worek; poddają polską historię prostym „demaskacjom”. [Brzozowska 2018: 292 ]

Ten cytat zawiera ślad dyskretnego wartościowania wrocławskiej premiery Termopil polskich Klaty. Sądzę, że autorka zastosowała w swojej ocenie nazbyt może wyrafinowane kryteria historycznoliterackie, że wyeksponowała autentyczne lub rzekome słabości spektaklu w sposób nieco restrykcyjny (nawiasem mówiąc, trzeba Brzozowskiej oddać to, iż sumiennie przywołała głosy krytyki teatralnej). Byłbym ostrożniejszy w ferowaniu historycznoliterackiego wyroku o premierze, która funkcjonuje w innym układzie odniesienia aniżeli dramat Micińskiego. Uwagi tej nie formułuję jednak, by forsować odmienną ocenę Termopil polskich Klaty; chodzi mi tylko o zaznaczenie faktu, iż w tej z lekka negatywnej waloryzacji wrocławskiej premiery dramatu wybrzmiał ton niesłyszalny w innych częściach rozprawy.

Lektura monografii $W z$ wierciadle idei stanowi wszakże intelektualną przygodę; czytelnik podąża za tokiem narracji autorki, już to dając się porwać jej interpretacyjnemu rozmachowi oraz kulturowej (w tym komparatystycznej) erudycji, już to ulegając sugestii pięknego stylu, który wysublimowaniem swoim i zwiewnością znakomicie przylega do przedmiotu. Odkrywane przez Brzozowską ideowe i artystyczne przestrzenie xIX-wiecznej formacji kulturowej - reprezentowane w książce przez teksty różnogatunkowe - z jednej strony poświadczają jej polifoniczną, niestabilną strukturę, z drugiej zaś ukazują niekiedy swój potencjał inspiracyjny dla wielu zjawisk i nurtów modernizmu xx-wiecznego.

\section{Bibliografia}

Brzozowska Sabina (2018), W zwierciadle idei. Literatura Młodej Polskikonteksty, Wydawnictwo IBL PAN, Warszawa.

Eustachiewicz Lesław (1982), Dramaturgia Młodej Polski. Próba monografii dramatu z lat 1890-1918, PWN, Warszawa.

Filipkowska Hanna (1973), Wśród bogów i bohaterów. Dramaty antyczne Stanistawa Wyspiańskiego wobec mitu, IBL PAN, Warszawa. 
Matuszek Gabriela (2001), Naturalistyczne dramaty, Universitas, Kraków. Sajewska Dorota (2002), „Norma to głupota, degeneracja zaś to geniusz”.

O jednostce zdezintegrowanej w „Śniegu” Stanisława Przybyszewskiego, w: Interpretacje dramatu. Dyskurs, postać, gender, red. Wojciech Baluch, Małgorzata Radkiewicz, Agnieszka Skolasińska, Joanna Zając, Księgarnia Akademicka, Kraków, s. 123-149.

Sajewska Dorota (2006), „Chore sztuki” - choroba/tożsamość/dramat.

Przemiany podmiotowości oraz formy dramatycznej $w$ utworach scenicznych przetomu XIX i XX wieku, Księgarnia Akademicka, Kraków.

Sławińska Irena, Kruk Stefan, wybór (1966), Myśl teatralna Młodej Polski. Antologia, wstęp Irena Sławińska, noty Bożena Frankowska, Wydawnictwa Artystyczne i Filmowe, Warszawa.

Taborski Roman (1987), „Śnieg” Stanisława Przybyszewskiego, w: Stanisław Przybyszewski, Śnieg, wstęp i przypisy Roman Taborski, Czytelnik, Warszawa, s. 5-12.

\section{Tomasz Sobieraj}

\section{On the Dynamics and Oppositions in Nineteenth-century Culture}

Sabina Brzozowska's monograph consists of a coherent collection of comparative and historical and literary studies of various artistic and ideological aspects found in selected works of Polish and European modernism. The author focuses on the dramas by Stanisław Wyspiański, Stanisław Przybyszewski, Tadeusz Rittner, Tadeusz Miciński and on the prose by Wacław Berent, Miciński and Thomas Mann. The interpretations of the works included in the monograph show a common area of European nineteenth-century culture, especially of the modernist period. Brzozowska's reading experience focused on uncovering the intertextual and comparative relationships between, for instance, Wyspiański's Wesele (The Wedding) and Mann's Buddenbrooks, Berent's Ozimina (Snow Crop) and Czarodziejska Góra (The Magic Mountain), Rittner and Ibsen. High art literature of the modernist period found its counterpoint in popular culture, including the new media. The author reconstructed this development dynamic of modernist culture in multiple versions.

Keywords: Young Poland; nineteenth century; modernism; drama; history; art. 
Tomasz Sobieraj - historyk literatury i kultury okresu pozytywizmu i Młodej Polski, edytor, kierownik Zakładu Literatury Pozytywizmu i Młodej Polski w Instytucie Filologii Polskiej Uniwersytetu im. Adama Mickiewicza w Poznaniu. Ostatnie publikacje książkowe: Stanisław Brzozowski. Przybliżenia (2016), Pozytywistyczne dylematy. Szkice o problemach literatury, filozofii i nauki (2016), Między konwencja a innowacja. Szkice o polskim dramacie i teatrze drugiej połowy XIX i początku XX wieku (2018), Artysta, sztuka i spoleczeństwo. Spory i polemiki wokót „Confiteor” Stanistawa Przybyszewskiego (2019). Najnowsze zainteresowania badawcze: krytyka literacka i teatralna drugiej połowy XIX i początku Xx wieku, związki literatury z przyrodoznawstwem. 